DOI: $10.20472 /$ TE.2017.5.2.006

\title{
IT'S NOT JUST CHILD'S PLAY: HOW TO CREATIVELY PROMOTE LEARNING FOR CHILDREN WITH ASD
}

\section{KATHY RALABATE DOODY}

\begin{abstract}
:
Play develops skill across all developmental domains in early childhood: cognitive/academic, communication/language, social-emotional, physical, and adaptive. Children with ASD often refrain from engaging in any type of play, or they may prefer play that is highly repetitious, sensory-based and of a "cause/effect" type. Encouraging a child with ASD to engage in novel types of play can be challenging, especially if the child has limited play skills in his repertoire. However, it is critically important that we discover ways to increase play skills of children with ASD. This article will discuss strategies for teaching and encouraging novel play for children with ASD. Strategies to consider are visual supports, such as video modeling, or social narratives, and reinforcement-based strategies: the Premack Principle or utilizing an existing area of interest.
\end{abstract}

\section{Keywords:}

autism, autism spectrum disorder, ASD, play

JEL Classification: 129

\section{Authors:}

KATHY RALABATE DOODY, State University of New York (SUNY), Buffalo State, United States, Email: krdoody@buffalo.edu

\section{Citation:}

KATHY RALABATE DOODY (2017). It's not just child's play: How to creatively promote learning for children with ASD. International Journal of Teaching and Education, Vol. V(2), pp. 93-104., 10.20472/TE.2017.5.2.006 


\section{Introduction}

In January, 2016, the World Health Organization cited the prevalence of autism spectrum disorder ("ASD") as 1 in every 160 children. The actual prevalence may be higher, as it is difficult to establish an accurate rate of incidence. In all probability, this is due to differing mechanisms used to report ASD worldwide. Additionally, ASD reporting is completely absent in some countries globally, particularly those with high levels of financial hardship. Some consistencies across the world have been noted in recent years, however. For example, Asia and Europe employ similar methods of reporting, and indicate an incidence of ASD that ranges between $1 \%$ and $2 \%$ of their total populations (Centers for Disease Control and Prevention [CDC], 2016).

In the United States, latest figures (2016) reflect an incidence of 1 in every 68 children, further broken down to 1 in 42 boys and 1 in 189 girls (CDC). This figure was derived from a reporting mechanism which sampled the total number of 8 year old children, living in 11 predetermined states of the United States, who had been given a clinical diagnosis of ASD as of 2010. It was felt that these states reflected a representative sample of the entire country. The sample states included Alabama, Arizona, Arkansas, Colorado, Georgia, Maryland, Missouri, New Jersey, North Carolina, Utah, and Wisconsin. This figure is felt to reflect the incidence of ASD in the United States as a whole (CDC, 2016). However, the current prevalence of ASD appears to be increasing, even given the new diagnostic criteria set forth by the Diagnostic Statistical Manual-5 ("DSM") in May of 2013 which many felt would reduce the number of children meeting diagnostic criteria for an ASD (Happé, 2011).

In the past edition of the DSM, we saw a differentiation of autism into five various subtypes ranging in severity level. In the 2013 iteration of the DSM, we now see three of the five subtypes of autism combined or collapsed into a new category, simply called an autism spectrum disorder or ASD. The three subtypes of autism which were collapsed into one ASD were autism (classical), Asperger's Syndrome, and Pervasive Developmental Delay, Not Otherwise Specified (PDD-NOS). Additionally, ASDs are now further classified by level of severity, ranging from levels one to three. A Level One severity type correlates to some degree with two of the previous subtypes of autism, Asperger Syndrome and PDD-NOS. A child diagnosed with a Level One ASD would require minimal amounts of support. A diagnosis of Level Two severity indicates the need for some support, and equates, in loose terms, to the mid-point of the spectrum, or what was formerly called Classical Autism or Kanner's Syndrome. The highest level of need would be seen in a child diagnosed as a Level Three, who would most likely require support in all areas of his/her daily activities, including feeding, dressing, toileting, and caring for personal safety (APA, 2013). 
In accordance with the DSM-5, an ASD can manifest socially, communicatively, and/or behaviorally. Individuals with ASD will demonstrate various levels of difficulty in engaging with others, comprehending spoken language, expressively communicating with others, and/or demonstrating appropriate behavior, particularly when responding to environmental stimuli or to routines. Additionally, the DSM-5 also now considers atypical responses to sensory stimulus (over-reactivity, under-reactivity, or a combination of both) as one of the listed components of the diagnostic criteria for ASD. One other diagnostic component of the DSM-5 that is of particular interest to educators and parents is the observed pervasive difficulty among children on the spectrum to engage in any type of play (APA, 2013).

The DSM-5 is quite similar in scope and purpose to the International Statistical Classification of Diseases and Related Health Problems, Tenth Edition ("ICD-10") which is used worldwide to diagnose autism spectrum disorder. Studies demonstrate an approximate $56 \%$ overlap in eventual diagnosis in young children between the DSM-5 and the ICD-10 (Wilson, Gillan, Spain, et al., 2013), so although there are some differences, there are obvious similarities. For example, the ICD-10 also lists deficits in play skills (imaginative, symbolic, spontaneous, etc.) as one attribute of children with autism, which parallels what we see in the DSM-5 (World Health Organization, 1993). Although there are some differences between the DSM V and the ICD-10, it is worth noting that both diagnostic checklists reference the inability to engage in play as part of their inclusionary criteria for an ASD.

Globally, we know that the incidence of ASD appears to be increasing. We also know that this population of individuals will continue to need support to ensure the best possible outcomes while increasing success for children. Worldwide, we are realizing the critical need for skill development in children with ASD, while providing holistic instruction, as much as possible, across all developmental domains. We also know that children learn through play, as it is their main occupation for discovering and exploring the world around them (Sheridan, Harding, \& Meldon-Smith, 2001). It has never been more important to support and foster play skills in all children, but particularly those with ASD who struggle to learn through many vehicles traditionally employed by early childhood educators.

This article will discuss why play is important for the cognitive development of young children with ASD. Next, the article with discuss the types of play preferred by children with ASD, and describe the characteristics of ASD which align to this unique type of play. The article will review various types of play, and explain why children with ASD prefer the types of play they do. Lastly, the article will present strategies for introducing novel play for children with ASD and will highlight the benefits and implications of these plays skills for children across home, school, and community-based settings. 


\section{Play}

All children engage in play as a means of exploration and learning. Play develops skill across all developmental domains in early childhood: cognitive/academic, communication/language, social-emotional, physical, and adaptive. In regard to play, early childhood educators are still informed by the work of Mildred Parten, who researched and characterized play by type (1932). Although current play experts have expanded her work to some degree, today we largely still follow the framework set into place by her research study which examined the "social participation" of young children engaged in free play. Each type is unique, although there is some inter-connectedness noted between play and its specific role.

Solitary play is the term used to describe a child who is playing alone, without regard to other children or materials around him. He does not demonstrate a desire to interact with others and only engages in isolate play. Parallel play, which is sometimes referred to as mirrored play, involves two or more children, manipulating the same materials, in largely the same way, and at the same time, but not connecting with each other. Cooperative play is fairly self-explanatory, as two or more children will join forces to work together with the same end result in mind. Cooperative play often involves some type of brainstorming or problem solving activity that is collaborative in nature. Sensori-motor play involves movement/motion and will incorporate sensory feedback, such as exploring the stimulating properties (visual, tactile, auditory, olfactory) of an object; this also includes manipulating materials in a hands-on manner, such as scooping, digging, pouring, or building. This is not to be confused with gross motor play, which involves movement of our long or large muscles (arms, legs, torso, etc.) Children engage in gross motor play by running, jumping, climbing, kicking, catching, etc. These preceding types of play are often discussed and/or classified together.

Another classification of play is that which involves building structures or employing creativity. Constructive play involves the use of smaller materials to build a larger configuration. In early childhood settings, we often see this facilitated by blocks, Legos, ramps, boxes, stacking cups, etc. Children can engage in constructive play collaboratively or in isolation. Dramatic play involves assuming the role of another, generally an adult who holds a very specific job or responsibility. Examples of dramatic play frequently observed in early childhood settings include children pretending to be construction workers, royalty, warriors, chefs, cashiers, truck drivers, or teachers. Symbolic play incorporates principles from dramatic and constructive lay and involves children using objects or materials in a highly-contrived or imaginative manner. The classic example of symbolic play is the child who picks up a rectangular box and pretends to speak into a cellular/mobile phone, or the child who sits under a table and pretends to be camping. 


\section{Preferred play of children with ASD}

Children with ASD often refrain from engaging in any type of play. Or, we may see very specific, repetitious, and preservative types of play favored by children on the spectrum. Doody and Mertz (2013) speculated, and later confirmed that children with ASD preferred "cause/effect" types of play, particularly if it was highly-repetitious and stimulated one of their senses. In this study, which involved children who were and were not on the autism spectrum, researchers discovered that children in community-based, recreational settings, often opted to engage in play that was highly predictable (repetitious), sensorybased, and involved a distinct cause and effect reaction, as further described below.

\section{Three types of favored play}

Highly-predictable play is repetitious in nature. The motor movements of repetitious play are often demonstrated in succession, without departure or deviance. These motor movements might involve knocking over a block tower, or banging a toy against a tabletop in a series of rapid, similar movements. A child might rewind a pre-selected segment of a DVD, watching the same footage, over and over again, without ever allowing the film to progress beyond a certain point. This type of preferred play can be highly-routinized. We may see a child with ASD demonstrate anxiety or agitation when perseverative play is interrupted. Likewise, a child with ASD will most likely show some resistant behaviors if we try to redirect her play to a more functional type. Most likely, repetitious preservative play is preferred because the child with ASD remains in control and can predict what reaction her play will elicit. The child with ASD may derive comfort in this predictability, resulting in a self-soothing type of play.

Children with ASD often engage in activities that provide immediate and intense sensorybased feedback. Research has demonstrated that children with ASD often prefer to engage in activities that stimulate one or several senses simultaneously. These activities could include spinning or twirling of a toy or oneself, dangling objects for purposes of visual stimulation, or smelling, licking, or touching objects, regardless of their edible attributes (Gabriels, et. al., 2009). Children with ASD often engage in this type of play at older chronological ages than same-age peers with typical development. For example, many young children will incorporate spinning or rocking into an early stage of play. Eventually, however, their play will naturally develop and mature, evolving into a higher level of play (dramatic, symbolic, etc.) Children with ASD tend to engage in this type of play for longer periods of time, developmentally, and do not appear to "outgrow" the preference demonstrated for it. Additionally, this type of sensory-based play can often overtake a child's attention and it may prove very difficult to redirect the child or break his concentration from his activities. 
Lastly, cause and effect play also appears to be highly preferred by children with ASD. Cause and effect play involve toys or objects where one action necessitates a predictable reaction. The child, or user, is in control of the action, so is therefore in control of the reaction. An example of a cause/effect toy is a pop-up toy. Generally, the toy has three or four choices of actions: a button to push, a wheel to turn, and a lever to slide. For each action, there is a corresponding reaction, as a ball or object may pop up directly adjacent to the wheel or button the child activated. Every time the button is activated, for example, a giraffe pops up, so the child is able to predict what response his action will elicit in the toy and when. Children with ASD often engage with cause/effect toys for period of time and appear to enjoy the direct correlation between their action and the toy's response (Holmes \& Willoughby, 2005).

\section{What does this mean?}

We know children with ASD tend to prefer engaging in isolate, solitary play of a predictable and sensory nature, as discussed above We also know they tend to prefer play that is sensory-based, and will often engage in sensori-motor play. We may also see children with ASD engage in gross motor play, most specifically, running, climbing, jumping, or spinning. However, this function of this type of play often appears to be rooted in sensory-seeking behaviors, as opposed to the social purposes of throwing of ball during a reciprocal game of catch, for example.

What type of play do children with ASD avoid? Due to the social-emotional issues that we often observe in children with ASD, we find that they shy away from play that involves another. During parallel play, the child with ASD does not appear to be mindful of the child sitting adjacently to him. Because children with ASD struggle to interact with others, we rarely see them engaging in cooperative play as the direct interaction with another child, loss of control, and lack of predictability may provoke anxiety.

Constructive, dramatic, and symbolic play are also challenging for children with ASD. One explanation for this difficulty may lie in the Theory of Mind mechanism. This mechanism dictates that an individual place himself in the metal shoes of another, to ascertain how the other may believe, think, or feel. Acquisition of the Theory of Mind mechanism is developed much later in children with ASD than those without, and some children on the spectrum may never develop the Theory of Mind mechanism (BaronCohen, 1989). Because of this, children with ASD may not be able to engage in any sort of play that involves pretending or role-playing, for example. It is difficult for a child to pretend she is a firefighter, for example, that a tower of blocks could be constructed into a toy bridge, or that a box is a castle, without ability to exercise the Theory of Mind. The absence of the Theory of Mind significantly inhibits the ability of a child with ASD to engage in pretend play of any sort (Verbalis, et al., 2008). 


\section{Implementation of visual supports}

Encouraging a child with ASD to engage in novel types of plan can be challenging, especially if the child has limited play skills in his repertoire. Most children with ASD do not learn well incidentally but instead benefit from a structured explicit teaching approach, to provide the child with direct instruction and guidance while acquiring the new skill ((Lovaas, 1987). One way to provide explicit instruction for children with ASD is through the use of visual supports. Research has demonstrated that novel play skills can be taught to children with ASD by employing guided, visual models which demonstrate to the child what he/she is expected to perform in an explicit and graphic way (Wolfberg, 1995). Additionally, past research studies affirm that visual supports provide a more effective instructional practice than the use of verbal instructions (Quill, 1997). Video modeling and social narratives are forms of visual supports that can be employed when teaching a child with ASD a new skill, namely a novel play activity.

Video modeling involves creating a highly-edited video, demonstrating the targeted appropriate play skills while removing or editing out any instances of inappropriate play skills. In this way, the video captures only footage of the type of play the child with ASD is intended to imitate. There are three different types of video modeling: self-video modeling where the actual child is depicted only demonstrating appropriate skills in the video, point of view modeling where the video is captured from the child's gaze or point of view; consequently, the camera only conveys what the child sees, and peer video modeling where the video captures another selected child (peer) demonstrating the targeted appropriate behavior. Video modeling is a highly effective teaching tool for children with ASD and could be employed when demonstrating appropriate play skills (Macmanus, MacDonald, \& Ahearn, 2015).

A social narrative (sometimes called a social story) is an individualized story, written from the child's point of view, allowing the child to voice thoughts and feelings through the narrative of the story. Similar to a video model, a social narrative is a visual depiction of the appropriate demonstration of the targeted behavior, represented in story form, with corresponding words and photos. A social narrative contains specialized types of sentences, including descriptive, directive, and perspective, each serving its own purpose. Perspective sentences can assist children with ASD in acquiring the Theory of Mind mechanism, as they provide a written and visual model to demonstrate how others feel and are impacted by our actions. Employing social narratives is a cost-effective and effective way to teach novel play skills to children with ASD while capitalizing on their strong visual skills (MacDonald, R., Clark, Garrigan, \& Vangala, 2005). 


\section{Reinforcement-based strategies}

Children with ASD respond favorably to positive reinforcement. Positive reinforcement provides a preferred or desirable reinforcer to a child after he/she has demonstrated appropriate behavior, thereby increasing the likelihood that the child would again repeat the appropriate behavior in the future (Alberto \& Troutman, 2013). Positive reinforcement can be used in several ways to entice children with ASD to try new types of play.

One way to use positive reinforcement is by employing the Premack Principle. The Premack Principle is strategy often used to increase the likelihood that a lesser-occurring behavior will occur more frequently, by employing positive reinforcement. The premise behind the Premack Principle is to introduce a less-preferred object, activity, or task, immediately followed by a highly-preferred task or item. The highly-preferred item serves as an automatic reinforcer for the child with ASD, rewarding him for his efforts and time spent with the lessor preferred object (Deris, \& DiCarlo, 2013). The Premack Principle is sometimes affectionately called "Grandma's Rule"; this statement refers to grandmother's promise to provide ice cream once the child has finished all of his green beans. Use of the Premack principal would entice children with ASD to attempt a new play skill, if the novel play activity is immediately followed up the novel play activity with a well-established and highly-preferred reinforce.

Utilizing an existing interest already possessed by a child with ASD is another effective use of reinforcement. Many children with ASD find television shows, movies, or characters highly motivating and reinforcing. This established interest could also be used as positive reinforcement as well as a learning tool (Baker, 2000). For example, if a child has a pre-occupation with Super Mario, this character could be utilized within other types of play, such as role playing (dramatic play), or building with Mario Legos (cooperative and constructive play). The child's established interest in a certain genre could prove advantageous when teaching a new play skill.

\section{Creatively promote learning through play}

Now that we have strategies in place to teach play, how can we encourage children to actually engage in play and learning? First, it is important to establish an environment that is conducive to play. Creating a warm and welcoming environment that naturally promotes play and learning is the first step. Play settings should be organized but still allow for naturalistic and free-form play. This environment can be created by first ensuring that there is adequate open space for play, absent any distractions such as electronics or "busy" décor. Additionally, the area should be child-friendly, with soft furnishings such as area rugs, upholstered furniture or bean bag chairs, natural or muted lighting, understated wall decorations, and enough floor or table space for play to naturally unfold. 
Next, it is important to provide toys and materials that naturally promote play. It is certainly a misconception that expensive and intricate toys are required to promote creative play. To the contrary, some of the richest forms of play are born from empty boxes, and everyday household items such as a wooden spoon and copper kettle. It is a natural inclination of children to observe and mimic adult behavior, so items such as old sunglasses, a mixing bowl, or watering can may serve as enticing props in a creative play scenario. Furthermore, recycled materials such as Popsicle sticks, yarn, or Styrofoam egg containers can be the basic foundation for powerfully creative play activities. Providing children with a diverse and resourceful array of materials can result in the creation of play in all types of novel forms and iterations, thereby encouraging the inception of play-based learning.

\section{Discussion and conclusion}

What are the benefits of play to a child with ASD? In the crucial early years of development, play engages children in a purposeful and valuable way. If children with ASD do not possess play skills, it is difficult for them to make use of naturally-occurring leisure time. Consequently, when left to their own devices during intervals of unstructured time, children with ASD may be observed engaging in two different types of practice which hinder development and present obstacles for learning: perseveration and stereotypy.

Although these terms may be unfamiliar to many outside of the field of autism study, they are only two well-known for professionals and parents working with children with ASD. Perseveration is the repetition of the same word, phrase, or gesture absent an appropriate triggering stimulus (Aurora, 2012). For example, verbal perseveration may include asking the same question over and over, even after it has been answered satisfactorily. Motoric perseveration may include the repeated ringing of a doorbell, even after the door has been opened. The practice of perseveration is sometimes referred to as being "stuck". Similar yet different is the practice of engaging in stereotypy, which is also observed in individuals with ASD.

Stereotypy is a form of self-stimulation and is illustrated by the practice of engaging in repetitive movements, often motoric or verbal, which does not appear contextually appropriate or with purpose (Cunningham \& Schreibman, 2008). Additionally, the practice of stereotypy often seems to result in internal reinforcement for the individual demonstrating it. This is sometimes referred to as the "pay-off". Examples of stereotypy include hand-flapping, rocking, jumping, or fist clenching. As also seen with perseveration, it can be difficult to compete with or "break" stereotypy, as the individual is experiencing intense internal satisfaction and pleasure while engaging in it.

However, one possible way to combat both perseveration and stereotypy is to teach a child to engage in purposeful and meaningful play, thereby alleviating the individual's 
need to engage in repetitious and non-meaningful activities. Children with ASD may not be naturally inclined to engage in play, making it even more important to teach how to play in an explicit and deliberate manner. Children with typical development may naturally turn towards constructive, dramatic, or symbolic play, while children with ASD may need to be guided towards play using the systematic and intentional strategies discussed in this article.

Although play is said to be the occupation of children, the benefits of play are certainly not limited to the childhood years. The ability to play can lead to the development of cognitive skills such as the concept of cause and effect, expressive object labeling, sequencing, patterning, or prediction. Although these skills are valued in academic settings, they also have authentic utility in real-life situations throughout an individual's lifespan, stretching far beyond the years a child would be engaging in play.

The ability to engage in play also has social-emotional benefits and can lead to the ability to interact appropriately with another, share, take turns, or collaboratively problem-solve. Although these are skill sets that we typically relate to young children, they are also assets later in life for teens and adults as they align well to life events occurring in personal, academic, or professional scenarios. School-aged children engage in more mature forms of play by participating in activities such as chess clubs, debate teams, or acapella ensembles. We often use a looser interpretation of play as adults as a way to socialize with others during an athletic activity, such as tennis or soccer, for example. Individuals of all ages engage in play by participating in socially acceptable computer games such as Grand Theft Auto ${ }^{\mathrm{TM}}$, GarageBand ${ }^{\mathrm{TM}}$, or Nintendo ${ }^{\mathrm{TM}}$.

Ralph Waldo Emerson once said "It is a happy talent to learn how to play". Some children will naturally learn to play, through incidental teaching, while children with ASD will mostly likely require a more deliberate and explicit instructional approach while learning to play. Regardless, we know that play is an effective learning vehicle for young children. Additionally, play is a means for children to appropriately interact with each other in social situations, thereby enhancing relationships and encouraging further invitations to collaboratively play. For these reasons, it is critically important that we discover ways to increase the play skills of young children with ASD, as their rising incidence indicates our schools and communities will experience increased numbers of children on the spectrum in the future. 


\section{References}

Alberto, P., \& Troutman, A. (2013). Applied behavior analysis for teachers (9th Ed.). Columbus, OH: Merrill.

American Psychiatric Association. (2013). Diagnostic and statistical manual of mental disorders: DSM-5 (5th ed.). https://doi.org/10.1176/appi.books.9780890425596

Arora, T. (2012). Understanding the perseveration displayed by students with autism spectrum disorder. Education, 132(4), 799+. $\quad$ Retrieved from http://link.galegroup.com/apps/doc/A297135682/SUIC?u=groves\&xid=48a47296

Baker, M.J. (2000). Incorporating the thematic ritualistic behaviors of children with autism into games: Increasing social play interactions with siblings. Journal of Positive Behavior Interventions, 2, 66 84. https://doi.org/10.1177/109830070000200201

Baron-Cohen, S. (1989). The autistic child's Theory of Mind: A case of specific developmental delay. Journal of Child Psychology and Psychiatry, 30, 285-297. https://doi.org/10.1111/j.14697610.1989.tb00241.x

Centers for Disease Control and Prevention. (2016). Prevalence of Autism Spectrum Disorder Among Children Aged 8 Years, 11 Sites, United States, 2010. Centers for Disease Control and Prevention, Surveillance Summaries, 63(2), 1-22.

Cunningham, A. B., \& Schreibman, L. (2008). Stereotypy in Autism: The Importance of Function. Research in Autism Spectrum Disorders, 2(3), 469-479. http://doi.org/10.1016/j.rasd.2007.09.006

Deris, A.R. \& DiCarlo, C.F. (2013). Back to basics: working with young children with autism in inclusive classrooms. Support for Learning, 28(2), 52-56. https://doi.org/10.1111/1467-9604.12018

Doody, K.R. \& Mertz, J. (2013). Preferred play activities of children with autism spectrum disorder in naturalistic settings. North American Journal of Medicine and Science, Special Issue of Autism, $6(3), 128-133$.

Gabriels, R.L., Agnew, J.A., Miller, L.J., Gralla, J., Pan, X., Goldson, E., Ledbetter, J.C., Dinkins, J.P., \& Hooks, E. (2009). Is there a relationship between restricted, repetitive, stereotyped behaviors and interests and abnormal sensory response in children with autism spectrum disorders? Research in Autism Spectrum Disorders, (2)4, 960-670.

Happé, F. (2011). Criteria, categories, and continua: Autism and related disorders in DSM-5. Journal of the American Academy of Child and Adolescent Psychiatry, 50(6), 540-542. https://doi.org/10.1016/j.jaac.2011.03.015

Holmes, E. \& Willoughby, T. (2005). Play behavior of children with autism spectrum disorders. Journal of Intellectual \& Developmental Disability, 30(3), 156-164. https://doi.org/10.1080/13668250500204034

Lovaas, I. (1987). Behavioral treatment and normal educational and intellectual functioning in young autistic children. Journal of Consulting and Clinical Psychology, 55, 3-9. https://doi.org/10.1037/0022-006X.55.1.3

MacDonald, R., Clark, M., Garrigan, E., \& Vangala, M. (2005). Using video modeling to teach pretend play to children with autism. Behavioral Interventions, 20, 225-238. https://doi.org/10.1002/bin.197 
Macmanus, C., MacDonald, R., \& Ahearn, W.H. (2015). Teaching and generalizing pretend play in children with autism using video modeling and matrix training. Behavioral Interventions, 30(3), 191-218. https://doi.org/10.1002/bin.1406

Parten, M.B. (1932). Social participation among preschool children. Journal of Abnormal and Social Psychology, 27(3), 243-269. https://doi.org/10.1037/h0074524

Quill, K.A. (1997). Instructional considerations for young children with autism: The rationale for visually cued instruction. Journal of Autism and Developmental Disorders, (27)6, 697-714. https://doi.org/10.1023/A:1025806900162

Sheridan, M.D., Harding, J., and Meldon-Smith, L. (2001). Play in early childhood: From birth to six years (2nd ed.). London: Routledge.

Verbalis, P.J., Robins, D.L., Boorstein, H., Klin, A.M., Babitz, T., Chawarska, K., Volkmar, F., Green, J., Barton, M., et al. (2008). The modified checklist for autism in toddlers: A follow-up study investigating the early detection of autism spectrum disorder. Autism, 12(5), 513-535.

Wilson, C.E., Gillan, N., Spain, D. et al. Comparison of ICD-10R, DSM-IV-TR and DSM-5 in an adult Autism Spectrum Disorder diagnostic clinic. Journal of Autism and Developmental Disorders, (43)2515, doi:10.1007/s10803-013-1799-6

Wolfberg, P. (1995). Enhancing children's play. In K. A. Quill (Ed.), Teaching children with autism: Strategies to enhance communication and socialization. Albany, NY: Delmar.

World Health Organization. (1993). The ICD-10 classification of mental and behavioural disorders: Clinical descriptions and diagnostic guidelines. Geneva: World Health Organization.

World Health Organization. (2013). Autism spectrum disorders \& other developmental disorders: From raising awareness to building capacity. Meeting Report, 1-40. 